\title{
ICT1 knockdown inhibits breast cancer cell growth via induction of cell cycle arrest and apoptosis
}

\author{
CHEN WANG $^{1,2^{*}}$, CHENLU LIANG $^{2,3^{*}}$, WEILIANG FENG ${ }^{2}$, XIANGHOU XIA $^{2}$, FENG CHEN $^{2}$, ENQI QIAO ${ }^{2}$ \\ XIPING ZHANG ${ }^{2}$, DAOBAO CHEN ${ }^{2}$, ZHIQIANG LING ${ }^{2}$ and HONGJIAN YANG ${ }^{1,2}$ \\ ${ }^{1}$ Department of Oncology, First Clinical Medical College, Wenzhou Medical University, Wenzhou, Zhejiang 325000; \\ ${ }^{2}$ Department of Breast Surgery, Zhejiang Cancer Hospital, Hangzhou, Zhejiang 310022; \\ ${ }^{3}$ Zhejiang Chinese Medical University, Hangzhou, Zhejiang 310053, P.R. China
}

Received October 11, 2016; Accepted January 23, 2017

DOI: $10.3892 / \mathrm{ijmm} .2017 .2913$

\begin{abstract}
The protein encoded by immature colon carcinoma transcript 1 (ICTI) is a component of the human mitochondrial ribosome, and is reported to be implicated in cell proliferation, viability and apoptosis of HeLa cells. This study was conducted to investigate the role of ICT1 in human breast cancer. Oncomine database was used to investigate ICTI expression in human breast cancer tissues compared to normal tissues. The results showed that ICTI was highly overexpressed in various human breast cancer subtypes. Then short hairpin RNA (shRNA)-mediated knockdown of ICTI was performed in human breast cancer ZR-75-30 and T-47D cells. A series of functional analysis, including MTT, colony formation and flow cytometry assays were conducted after ICTI knockdown. Our results demonstrated that knockdown of ICT1 significantly suppressed cell viability and proliferation through cell cycle arrest at the G2/M phase and induced apoptosis in breast cancer cells. Furthermore, knockdown of ICT1 altered signaling pathways associated with cell growth and apoptosis, including phospho-BAD (Ser112), phosphoPRAS40 (Thr246) and induction of phospho-AMPK $\alpha$ (Thr172). Additionally, it was further confirmed by western blot analysis that ICT1 knockdown altered the expression of apoptosis- or cell cycle-related proteins such as Bcl-2, caspase-3, CDK1, CDK2 and cyclin B. In conclusion, targeting ICT1 in breast cancer cells may provide a new strategy for breast cancer gene therapy.
\end{abstract}

Correspondence to: Dr Hongjian Yang, Department of Oncology, First Clinical Medical College, Wenzhou Medical University, 2 Fuxue Road, Wenzhou, Zhejiang 325000, P.R. China E-mail: yanghongjian3@163.com

\section{*Co-first authors}

Key words: immature colon carcinoma transcript 1, cell proliferation, colony formation, cell cycle, apoptosis

\section{Introduction}

Breast cancer is a major worldwide threat to women's health (1). It is the most common malignancy in females resulting in $\sim 40,000$ deaths/year in the United States (2). Breast cancer has been reported to be associated with reproductive and hormonal factors plus endogenous sex hormone levels (3). In addition, the metastasis of breast cancer frequently presents in regional lymph nodes, bone marrow, lung and liver, which primarily bypasses through the lymphatic system $(4,5)$. To prevent tumor growth and metastasis, various treatments including surgery, radiotherapy, chemotherapy, immunotherapy and combined strategies have been employed $(6,7)$. Advances in these therapies have shown to have a beneficial effect on the quality of life of breast cancer patients. However, no available therapy currently exists for patients with advanced, invasive and metastatic breast cancer (8). Hence, further exploration of the molecular mechanisms involved in breast cancer development and progression is still urgently needed. Human mitochondria are considered as semi-autonomous cell organelles with their own genome and are responsible for production of energy and regulation of cellular processes $(9,10)$. Immature colon carcinoma transcript 1 (ICT1) is a mitochondrial ribosome protein that belongs to a family of human mitochondrial translation release factors, which masters the termination stage of translation $(11,12)$. In addition, it is also recruited into the human mitochondrial ribosome as a functional peptidyl-tRNA hydrolase (13). A previous study showed that the ICT1 proteins are necessary for cell viability (14). Mutations of the Gly-Gly-Gln motif (GGQ motif) as well as knockdown of ICTl were found to lead to loss of cell viability (15). In HeLa cells, depletion of ICTI caused apoptotic cell death (14). Lentiviral-mediated RNA interference of $I C T 1$ significantly blocked gliboblastoma multiforme cell growth through inducing $\mathrm{G} 2 / \mathrm{M}$ cell cycle arrest (16). To date, the role of ICTI in breast tumor growth and spreading is unknown.

To uncover the biological function of $I C T I$ in breast cancer, the ICT1 mRNA expression pattern was analyzed using the Oncomine database. Furthermore, we conducted loss-of-function experiments on breast cancer cells to further confirm the biological function of ICT1. Our findings may contribute to a 
better understanding of the role of ICT1 in the regulation of breast cancer tumorigenesis.

\section{Materials and methods}

Oncomine dataset analysis. Microarray datasets for breast cancer were retrieved from the Oncomine database (https://www.oncomine.org) to investigate ICT1 expression in breast cancer by the following definition: gene name, ICT1; analysis type, cancer versus normal analysis. The cancer type was defined as breast cancer, and data type was mRNA.

Cell lines and culture. Six breast cancer cell lines (ZR-75-30, T-47D, MDA-MB-231, MDA-MB-435, MCF-7 and BT-474) and human embryonic kidney cells $293 \mathrm{~T}$ were provided by the Cell Bank of Shanghai Institute of Biochemistry Cell Biology, Chinese Academy of Sciences. ZR-75-30 and BT-474 cells were cultured in RPMI-1640 medium (HyClone, Logan, UT, USA) supplemented with $10 \%$ fetal bovine serum(FBS; S1810; Biowest, Nuaillé, France). MDA-MB-231, MDA-MB-435, T-47D and HEK293T cells were cultured in Dulbecco's modified Eagle's medium (DMEM) (HyClone) with 10\% FBS. MCF-7 cells were maintained in Modified Eagle's medium (MEM; HyClone) with 10\% FBS (S1810; Biowest). All cell cultures were incubated in a humidified $95 \%$ air atmosphere containing $5 \% \mathrm{CO}_{2}$ at $37^{\circ} \mathrm{C}$.

Construction of the lentivirus-based vector to infect breast cancer cells. According to the ICT1 sequence (NM_001545), two different shRNAs targeting ICT1 were designed using siRNA Construct Builder (http://www.genscript.com/rnai. html). Primers of shRNA(S1), shRNA(S2) and control shRNA were synthesized with the following sequences: 5'-GCTGTTAATGCTTGTCTATAACTCGAGTTATAGACA AGCATTAACAGCTTTTTT-3', 5'-GCAGAATGTGAACA AAGTGAACTCGAGTTCACTTTGTTCACATTCTGCTTT TTT-3' and 5'-GATCCTTCTCCGAACGTGTCACGTCTC GAGACGACGCACTGGCGGAGAATTTTTG-3', respectively. Each shRNA was ligated between the NheI and PacI sites downstream of the U6 promoter in the lentiviral vector pFH-L (Shanghai Hollybio, Shanghai, China) to generate Lv-shRNA (S1, S2 or Con). A mixture of the modified pFH-L plasmids and packaging vectors (pVSVG-I and pCMVAR8.92) were then cotransfected into $293 \mathrm{~T}$ cells using Lipofectamine 2000 (Invitrogen, Carlsbad, CA, USA), as suggested by the manufacturer's instructions.

For cell infection, human breast cancer ZR-75-30 and T-47D cells $(600,000$ cells/well) were seeded in 6-well plates and then infected with Lv-shICT1(S1), Lv-shICT1(S2), or Lv-shCon, respectively. After incubation for $192 \mathrm{~h}$, the infection efficiency was determined by detecting green fluorescent protein (GFP) expression under confocal fluorescence microscopy.

Real-time quantitative PCR (RT-qPCR) analysis. Total RNAs were extracted from cells infected with Lv-shICT1(S1), Lv-shICT1(S2), or Lv-shCon using TRIzol reagent (Invitrogen). First-Strand complementary DNA (cDNA) was generated from $1 \mu \mathrm{g}$ of total RNA in the presence of SuperScript ${ }^{\mathrm{TM}}$ reverse transcriptase and oligo $(\mathrm{dT})_{12-18}$ primer (both from Gibco-BRL): ICT1 RT-qPCR primer set, 5'-CAGCCTG GACAAGCTCTACC-3' and 5'-GGAACCTGACTTCTGCC
TTG-3'; actin RT-qPCR primers set, 5'-GTGGACATCCGCA AAGAC-3' and 5'-AAAGGGTGTAACGCAACTA-3'. The reaction mixture contained $2 \mathrm{X}$ SYBR Premix Ex Taq $10 \mu 1$, each primer $(2.5 \mu \mathrm{M}) 0.5 \mu \mathrm{l}$, cDNA $5 \mu \mathrm{l}$, and $\mathrm{ddH}_{2} \mathrm{O} 4.5 \mu \mathrm{l}$. Samples were performed on Bio-Rad Connet Real-Time PCR platform and initially denatured at $95^{\circ} \mathrm{C}$ for $1 \mathrm{~min}$, denatured at $95^{\circ} \mathrm{C}$ for $5 \mathrm{sec}, 40$ cycles of $20 \mathrm{sec}$ at $60^{\circ} \mathrm{C}$, and $10 \mathrm{~min}$ at $72^{\circ} \mathrm{C}$. The $2^{-\Delta \Delta \mathrm{Ct}}$ calculation method was used to analyze the relative expression of ICT1 to actin.

Western blot analysis. The expression level of ICT1 protein along using cell cycle and apoptosis regulatory proteins were analyzed in cells with western blotting. Briefly, the cells were harvested, washed with cold phosphate-buffered saline (PBS), and mixed with $2 \mathrm{X}$ sodium dodecyl sulfate (SDS) sample buffer [100 mM Tris-HCl (pH=6.8), 10 mM EDTA, 4\% SDS, $10 \%$ glycine]. Each sample of protein (30 $\mu \mathrm{g} /$ lane) was separated on $12 \%$ SDS-PAGE at $150 \mathrm{~V}$ for $1 \mathrm{~h}$, and then transferred to polyvinylidene fluoride) membrane (PVDF) at $300 \mathrm{~mA}$ for $2.0 \mathrm{~h}$. After blocking with $5 \%$ non-fat milk, the blots were incubated with primary antibodies: rabbit anti-ICT1 (1:1,000; Cat. no. \#AP20382b; Abgent, San Diego, CA, USA), rabbit anti-Bcl-2 (1:1,000; Cat. no. 2876), rabbit anti-caspase-3 (1:500; Cat. no. 9661) (both from Cell Signaling Technology, Danvers, MA, USA), rabbit anti-CDK1 (1:500; Cat. no. 19532-1-AP; Proteintech, Chicago IL, USA), rabbit anti-CDK2 (1:1,000; Cat. no. 2546; Cell Signaling Technology), rabbit anti-cyclin B (1:1,000; sc-2005, Santa Cruz Biotechnology, Inc., Santa Cruz, CA, USA) and rabbit anti-glyceraldehyde 3-phosphate dehydrogenase (GAPDH) (1:80,000 or 1:500,000; Cat. no. 10494-1-AP; Proteintech) at $4^{\circ} \mathrm{C}$ overnight. Subsequently, the membrane was incubated with a goat anti-rabbit horseradish peroxidase-conjugated secondary antibody (1:5,000; Santa Cruz Biotechnology, Inc.) and visualized by Bio-Rad Gel Doc XR+ Imaging system (Bio-Rad, Hercules, CA, USA).

3-(4,5-Dimethylthiazol-2-yl)-2,5-diphenyltetrazolium bromide (MTT) cell viability assay. Cells were seeded onto 12-well culture plates at 2,000 cells/well and cultured for 1, 2, 3, 4 and 5 days before adding MTT plus acidic isopropanol. After incubation for $4 \mathrm{~h}$ at $37^{\circ} \mathrm{C}, 100 \mu \mathrm{l}$ acidic isopropanol containing $10 \% \mathrm{SDS}, 5 \%$ isopropanol and $0.01 \mathrm{~mol} / 1 \mathrm{HCl}$ was then added to stop the reaction. The absorbance of the reaction mixture was measured at $595 \mathrm{~nm}$ in a UV/VIS spectrophotometer (U-2000; Hitachi, Tokyo, Japan).

Colony survival assay. To further assess the proliferation ability of the human breast cancer cells, colony formation assay was performed in ZR-75-30 and T-47D cells. On the third day following infection, cells were seeded on 6-well culture plastic at an initial cell density of 400 cells/well and allowed to incubate for 6 days at $37^{\circ} \mathrm{C}$ under $5 \% \mathrm{CO}_{2}$ atmosphere. The cell pellet was washed with ice-cold PBS, fixed with paraformaldehyde, and subsequently stained with crystal violet for $20 \mathrm{~min}$. Capability of colony formation was examined under a fluorescence microscope. The number of colonies consisting of $>50$ cells were counted and quantified.

Cell cycle distribution analysis by flow cytometry. The Lv-shCon- and Lv-shICT1(S1)-infected cells were seeded at 

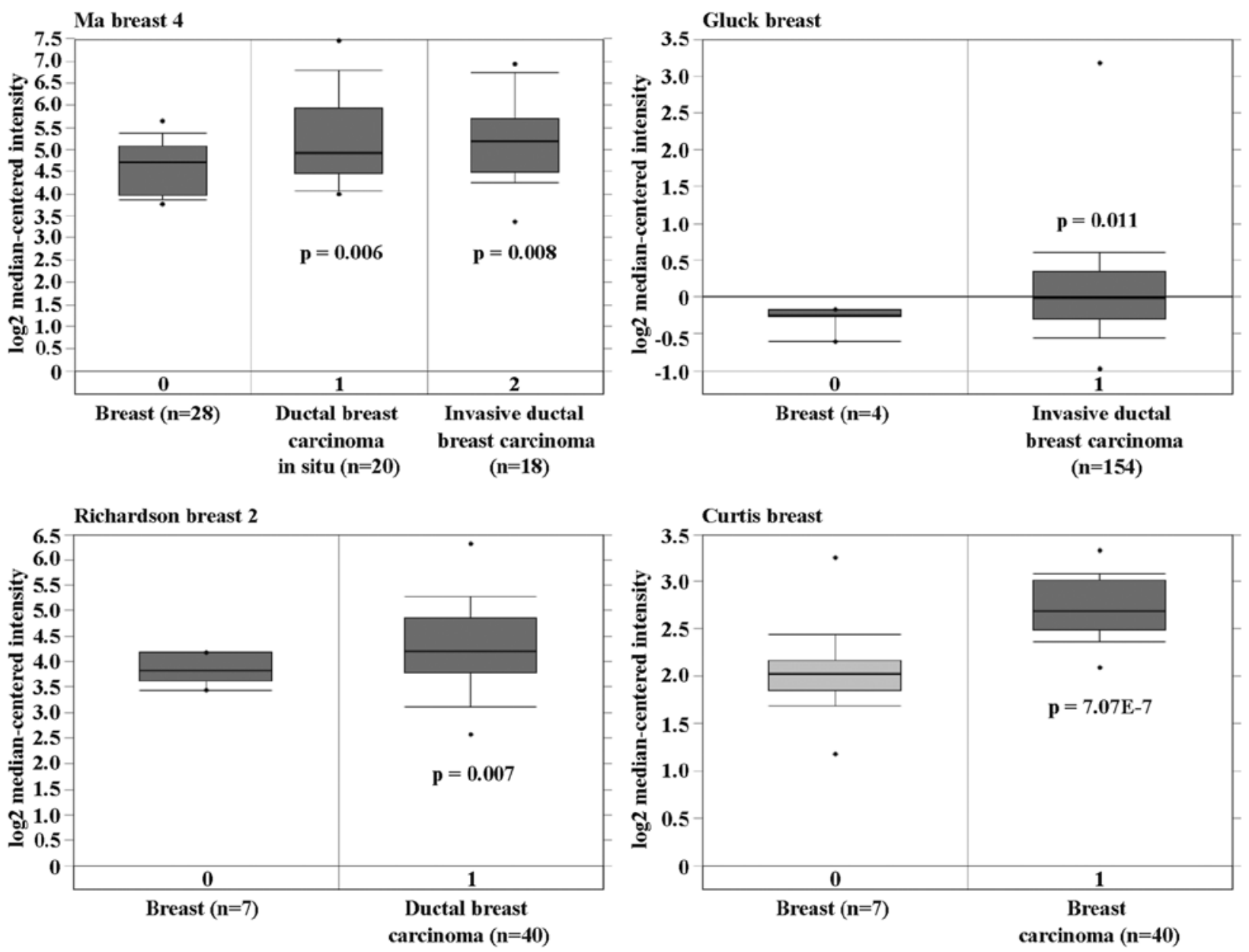

Figure 1. Immature colon carcinoma transcript 1 (ICT1) mRNA expression is overexpressed in various breast cancer types. Box plots showing differences in ICT1 mRNA expression in breast, breast carcinoma, blood, male breast carcinoma, tubular breast carcinoma and ductal breast carcinoma in situ. Data were extracted from the Oncomine database and shown as $\log 2$ transformation of median-centered intensities. Black lines represent the median, minimum and maximum values.

40,000 cells in a 6-well plate and incubated for $96 \mathrm{~h}$. The cells were harvested, washed twice with pre-cold PBS, and fixed in ice-cold $75 \%$ ethanol for $2 \mathrm{~min}$. The samples were digested with RNase, dyed with propidium iodide and analyzed on a flow cytometer (BD Biosciences, Franklin Lakes, NJ, USA).

Cell apoptosis. Analysis of the cell apoptosis after $40 \mathrm{~h}$ of infection was carried out using Annexin V-APC/7-AAD labeling (Apoptosis Detection kit; KeyGEN, Nanjing, China) on a FACSCalibur (BD Biosciences) according to the manufacturer's instructions. The proportion of ZR-75-30 cells were categorized as viable (Annexin $\mathrm{V}^{-} / 7-\mathrm{AAD}^{-}$), necrotic (Annexin $\mathrm{V}^{-} / 7-\mathrm{AAD}^{+}$), early apoptotic (Annexin $\mathrm{V}^{+} / 7-\mathrm{AAD}^{-}$), and late apoptotic (Annexin $\mathrm{V}^{+} / 7-\mathrm{AAD}^{+}$).

Detectional intracellular signaling pathways. To simultaneously evaluate the level of phosphorylation or cleavage of 18 significant molecules, the PathScan Intracellular Signaling array kit was utilized (Cell Signaling Technology). ZR-75-30 cells were washed twice with ice-cold PBS and lysed in $1 \mathrm{ml}$ lysis buffer. After incubation with the array blocking buffer, the mixtures were treated at room temperature with lysate for $1 \mathrm{~h}$. Reactions were incubated overnight at $37^{\circ} \mathrm{C}$, treated with monoclonal antibody cocktail, and reacted with HRP-conjugated streptavidin in substrate buffer. The chemilu- minescence signal was captured by a ChemiDoc XRS imaging system (Bio-Rad).

Statistical analysis. Each experiment was repeated at least three times and the results are shown as mean \pm standard deviation (SD). SPSS 19.0 (SPSS, Chicago, IL, USA) was used for statistical analyses. Student's t-test was performed to compare differences between groups. A p-value $<0.05$ indicates significant difference.

\section{Results}

ICT1 is overexpressed in human breast cancers. To investigate the correlation between ICTI and human breast cancer, the ICT1 expression pattern in normal and cancer samples were initially determined from the publicly available Oncomine database (https://www.oncomine.org). Four data sets were identified, including normal blood, breast carcinoma, male breast carcinoma, tubular breast carcinoma and ductal breast carcinoma in situ. Importantly, significant overexpression of ICT1 was found in breast carcinoma compared with breast $(\mathrm{p}=7.07 \mathrm{E}-7)$, in male breast carcinoma compared with blood and breast $(\mathrm{p}=0.003)$, in tubular breast carcinoma compared with breast $(p=4.73 \mathrm{E}-24)$, and in ductal breast carcinoma compared with breast $(\mathrm{p}=6.35 \mathrm{E}-4)$ (Fig. 1). Here, the results 
A

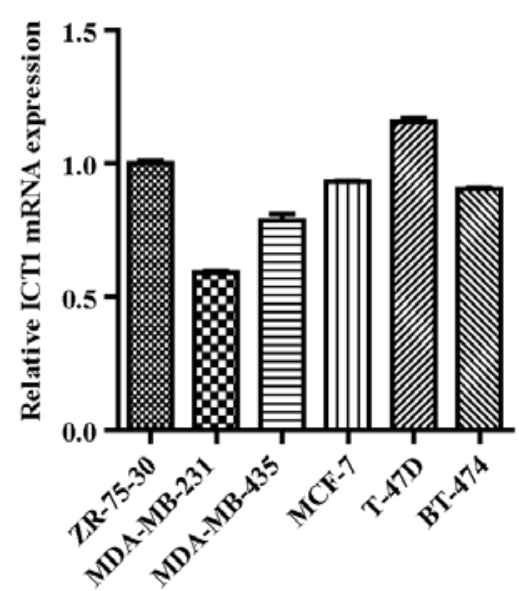

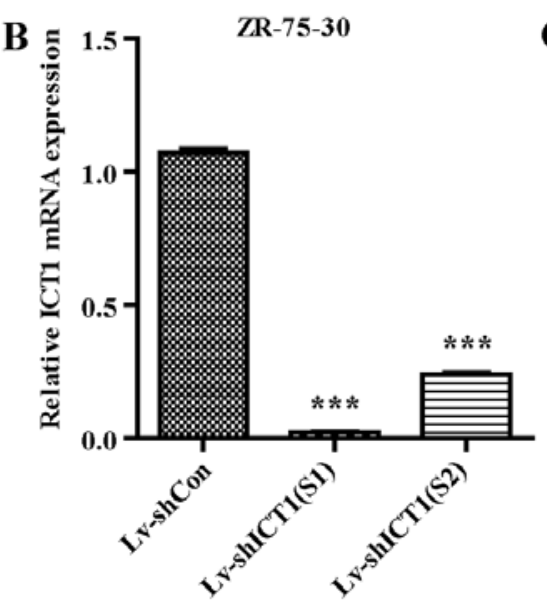

$\mathrm{C}$

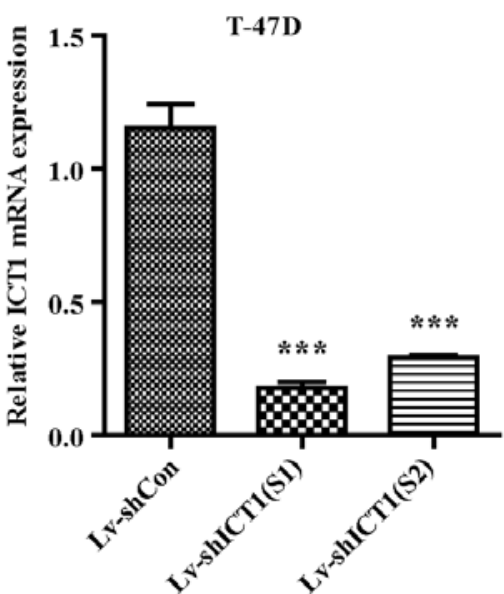

D

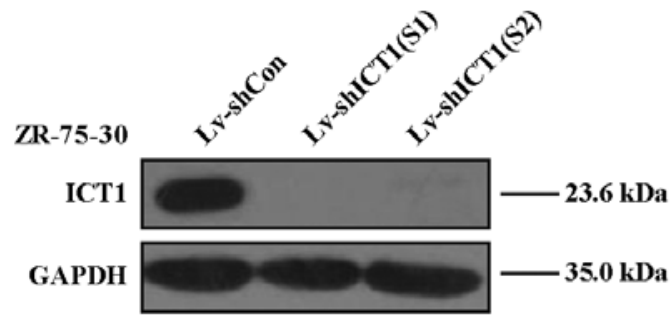

E

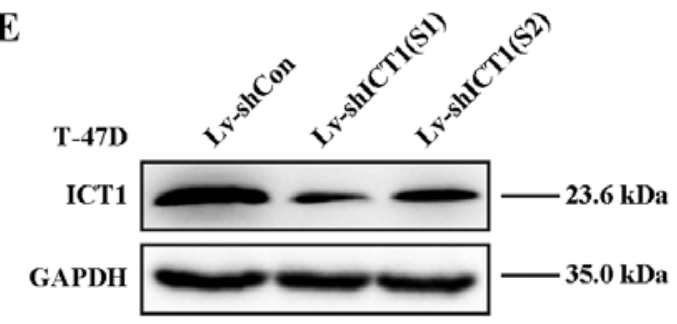

Figure 2. A lentivirus carrying short hairpin RNA (shRNA) effectively knocked down immature colon carcinoma transcript 1 (ICT1) gene and protein expression in human breast cancer ZR-75-30 cells. (A) The mRNA levels of ICT1 were determined in several breast cancer cell lines. (B and C) Lentiviral-mediated shRNA interference significantly reduced ICT1 expression at the mRNA level in the ZR-75-30 and T-47D cells using RT-qPCR analysis. (D and E) Lentiviral-mediated shRNA interference significantly reduced ICT1 in the ZR-75-30 and T-47D cells at the protein level using western blot analysis. Actin and GAPDH were used as internal controls for RT-qPCR and western blot analysis, respectively. Quantitative data are expressed as mean \pm standard deviation (SD) of three repeated experiments, ${ }^{* * *} \mathrm{p}<0.001$

demonstrated that ICT1 was highly overexpressed in various human breast cancer subtypes.

Expression of ICT1 mRNA and protein levels are clearly inhibited in breast cancer cells following knockdown by shRNA. To further investigate the biological function of ICT1 in breast cancer in vitro, we determined the expression of ICT1 in several breast cancer cell lines using RT-qPCR analysis. As shown in Fig. 2A, ZR-75-30 and T-47D cells presented higher ICT1 expression, which thus were chosen for the subsequent analysis. To conduct loss-of-function analysis on breast cancer cells, ICT1 expression was specifically knocked down in the ZR-75-30 and T-47D cells by lentivirus-mediated RNA interference technology (shRNA). We evaluated the knockdown efficiency using RT-qPCR and western blot analysis. These results demonstrated that the ICT1 mRNA was significantly reduced in the Lv-shICT1(S1) and the Lv-shICT1(S2) groups compared with that in the negative controls in the ZR-75-30 ( $<<0.001)$ (Fig. 2B) and T-47D $(\mathrm{p}<0.01)$ (Fig. 2C) cells. Consistently, ICT1 protein expression was markedly decreased in the ZR-75-30 and T-47D cells transduced with lentivirus carrying Lv-shICT1(S1) or Lv-shICT1(S2) as determined by western blotting (Fig. 2D and E). These findings demonstrated that the ICTI transcriptional and translational levels were successfully reduced by lentivirus-mediated delivery of shRNA in breast cancer cells.

ICT1 knockdown suppresses the proliferative and colony formation capabilities of human breast cancer cells. MTT assays were performed to determine cell proliferation 1, 2, 3,
4 and 5 days post-infection. On the 4th and 5 th day, the cell viability was significantly decreased in the Lv-shICT1(S1)or Lv-shICT1(S2)-treated groups compared to the control shRNA-treated ZR-75-30 and T-47D cells (Fig. 3A).

ZR-75-30 and T-47D cells were then used for colony formation assay. Briefly, colonies were grown for 6 days and stained with crystal violet. As shown in Fig. 3B, a smaller number of colony-forming cells was observed under fluorescence microscope after Lv-shICT1(S1) or Lv-shICT1(S2) infection. A further examination of colony numbers showed that the number of colonies was significantly reduced in the shICT1(S1)- and shICT1(S2)-infected cells compared with the shCon-infected cells (Fig. 3C). These findings indicate that ICTI knockdown inhibited human breast cancer cell proliferation and colony formation ability and Lv-shICT1(S1) displayed more powerful ability to inhibit cell proliferation.

Knockdown of ICT1 causes cell cycle arrest at G2/M phase in breast cancer cells. To investigate how ICT1 regulates cell proliferation, flow cytometry was used to examine cell cycle distribution in the ZR-75-30 and T-47D cells transduced with Lv-shCon or Lv-shICT1(S1) (Fig. 4A and C). Statistical analysis further demonstrated that the percentage of cells in the $\mathrm{G} 2 / \mathrm{M}$ phase were markedly increased in the Lv-shICT1(S1) group in both the T-47D (p<0.001) (Fig. 4B) and ZR-75-30 $(\mathrm{p}<0.001)$ (Fig. 4D) cells. These findings suggest that downregulation of ICT1 significantly arrested the cell cycle at the $\mathrm{G} 2 / \mathrm{M}$ phase in the breast cancer cells. 
A

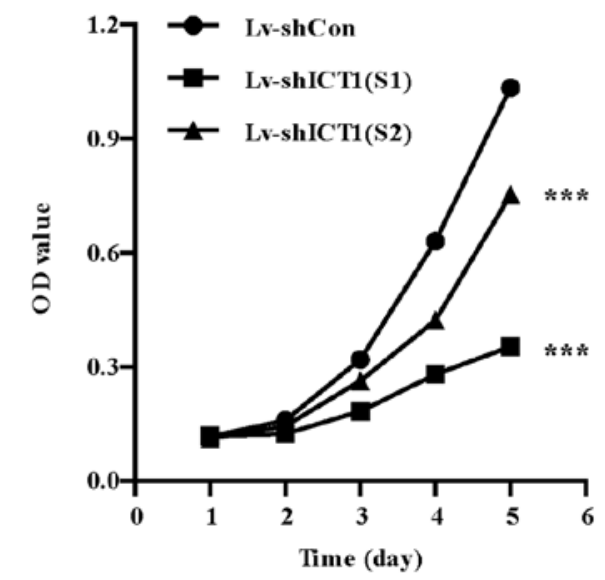

B

C
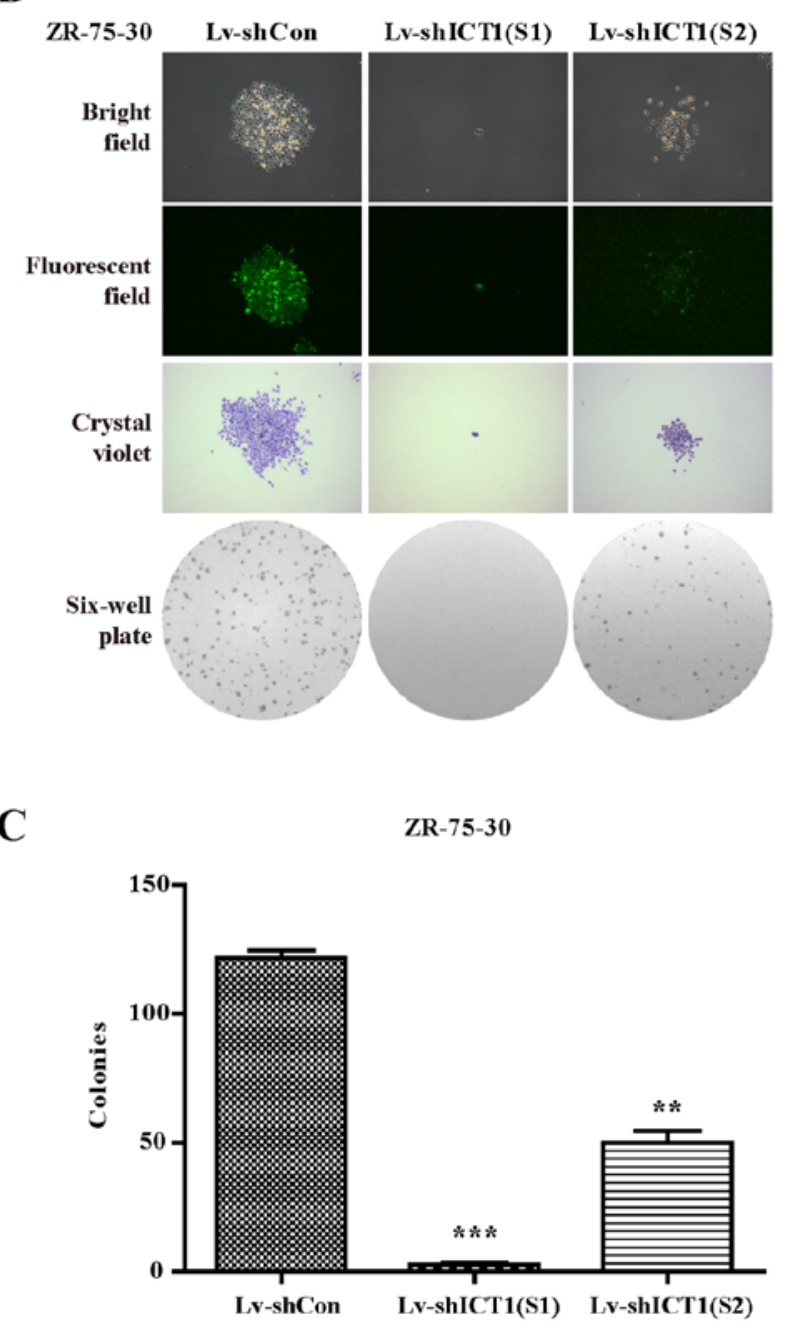

ZR-75-30

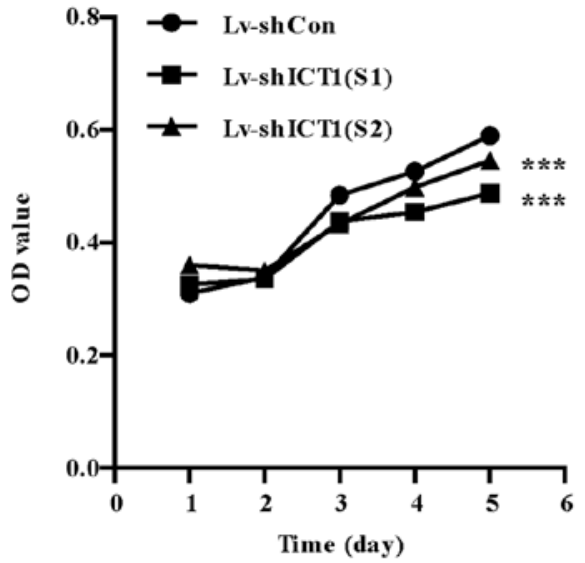

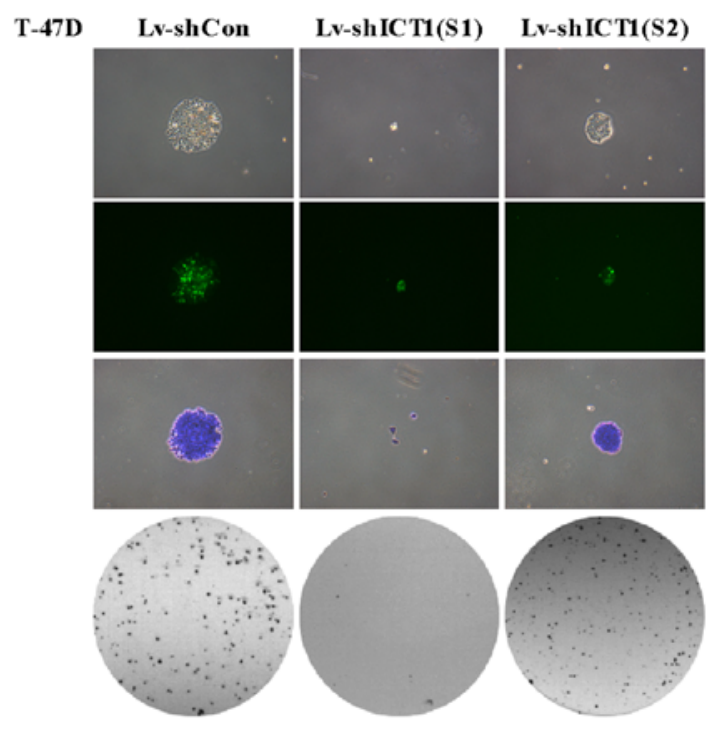

T-47D

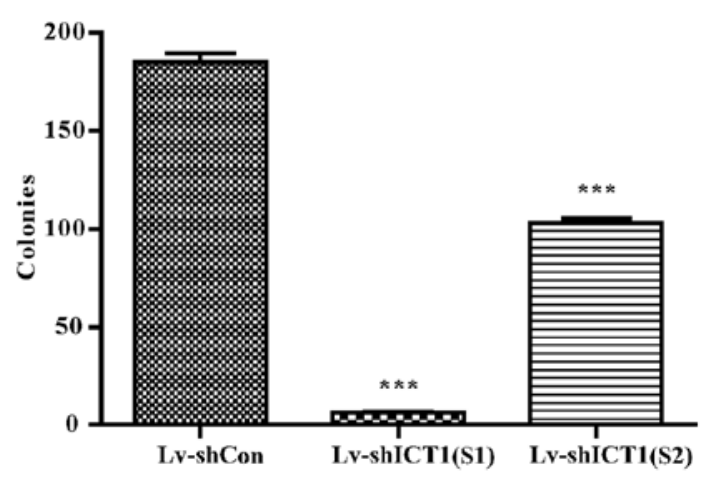

Figure 3. Proliferation and colony-forming ability were impaired in the immature colon carcinoma transcript 1 (ICT1)-knockdown breast cancer cells. (A) Cell proliferation was monitored 1,2,3,4 and 5 days by MTT assay, and significant inhibition was observed on the 4th and 5th day in the ZR-75-30 and T-47D cells with ICTI knockdown. (B) Downregulation of ICT1 exhibited an inhibitory effect on the cell colony formation of ZR-75-30 and T-47D cell lines. At day 6 of culture, representative colonies were photographed under a fluorescence microscope. (C) ICT1 depletion repressed the increase in colony number as compared to the control. Quantitative data are expressed as mean \pm standard deviation (SD) of three repeated experiments, ${ }^{* *} \mathrm{p}<0.01$ and ${ }^{* * * *} \mathrm{p}<0.001$.

Knockdown of ICT1 promotes cell apoptosis. To verify whether ICTI is involved in regulating ZR-75-30 cell apoptosis, 7-AAD and Annexin V-APC staining was performed (Fig. 5A). The

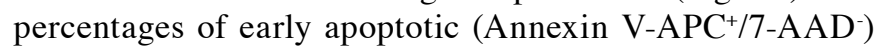

and late apoptotic (Annexin $\mathrm{V}-\mathrm{APC}^{+} / 7-\mathrm{AAD}^{+}$) cells were significantly higher in the ICTI-knockdown group than that in the control group $(15.28 \pm 0.41$ vs. $4.62 \pm 0.24$ and $9.84 \pm 0.19$ vs. $5.3 \pm 0.16$ ) (Fig. 5B). These results indicated that knockdown of 
A

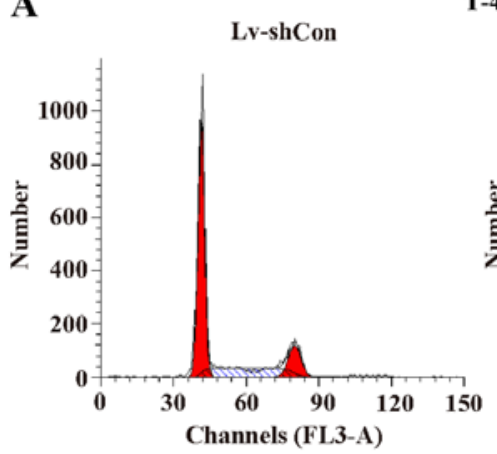

T-47D

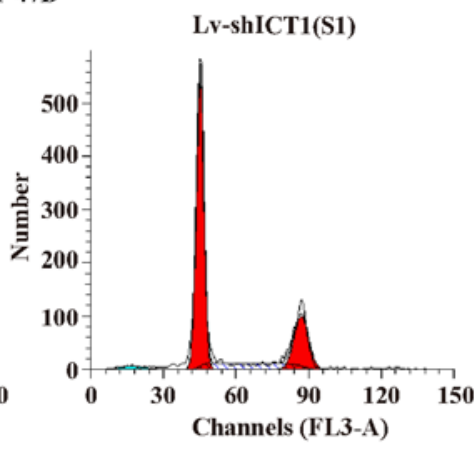

ZR-75-30

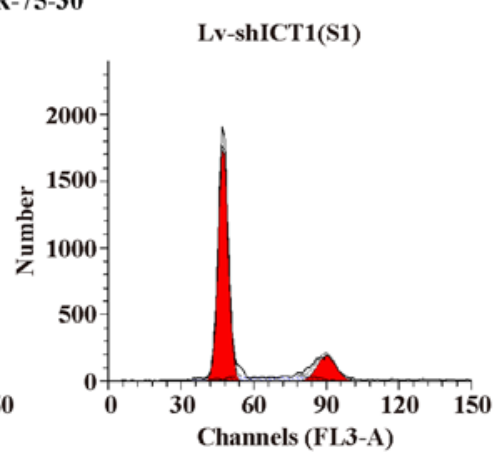

B

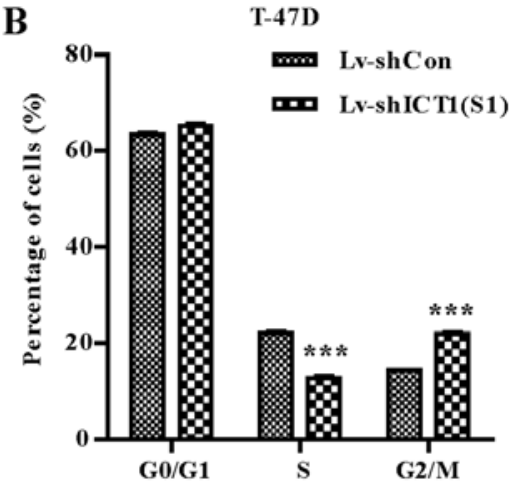

D

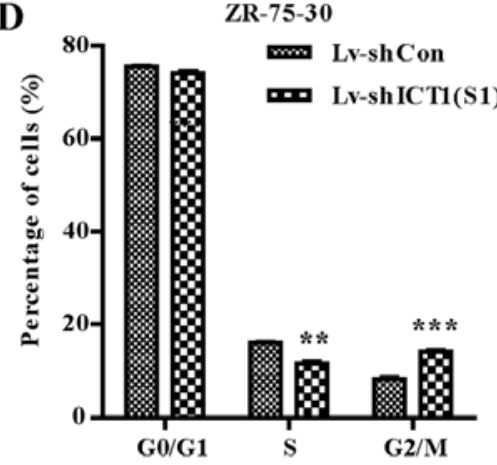

Figure 4. Knockdown of the immature colon carcinoma transcript 1 (ICT1) caused cell cycle arrest in human breast cancer cells. (A and C) Cell cycle distribution of Lv-shCon- and Lv-shICT1(S1)-treated cells was analyzed by flow cytometry in the T-47D and ZR-75-30 cell lines. (B and D) ICTI deficiency produced an increase in the percentage of cells in the G2/M phase in both the T-47D and ZR-75-30 cell lines. Quantitative data are expressed as mean \pm standard deviation (SD) of three repeated experiments, ${ }^{* *} \mathrm{p}<0.01,{ }^{* * * *} \mathrm{p}<0.001$.

A

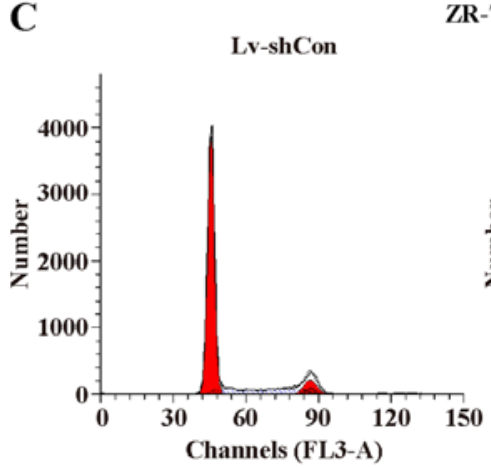

ZR-75-30
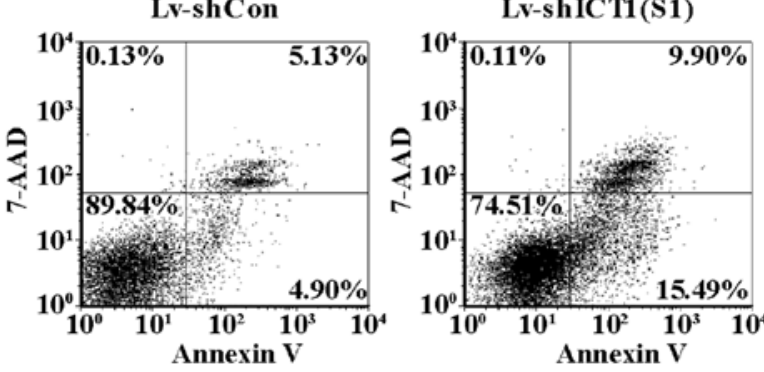

B

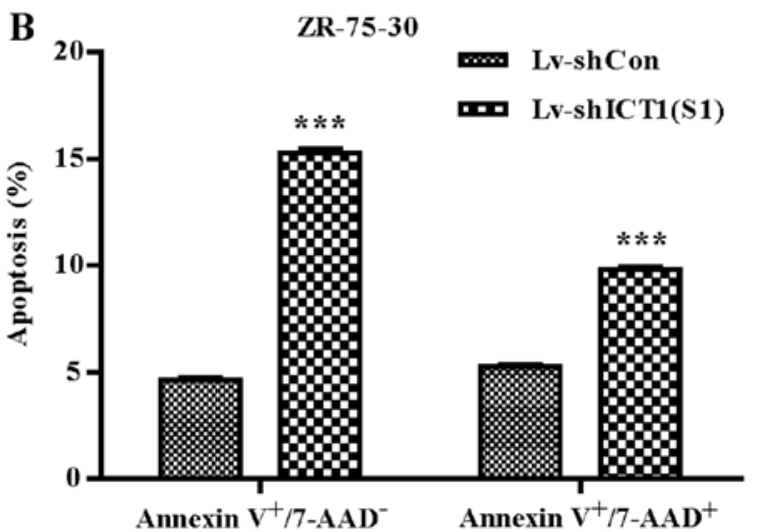

Figure 5. Immature colon carcinoma transcript 1 (ICT1) knockdown increased the percentages of the early and late apoptotic breast cancer cells. (A) The viable, necrotic, early apoptotic and late apoptotic cells treated with Lv-shCon or Lv-shICT1(S1) were analyzed by Annexin V-APC/7-AAD flow cytometry. (B) Accumulation of early apoptotic and late apoptotic cells was observed in the Lv-shICT1(S1) group when compared with the Lv-shCon group. Quantitative data are expressed as mean \pm standard deviation (SD) of three repeated experiments ${ }^{* * * *} \mathrm{p}<0.001$
ICT1 significantly increased the percentages of early and late apoptotic breast cancer cells.

Depletion of ICT1 disrupts Bad (Ser112), PRAS40 (Thr246), and AMP-activated protein kinase $\alpha(A M P K \alpha)($ Thr172) phosphorylation in ZR-75-30 cells. To investigate the molecular mechanism of ICT1-mediated cell proliferation and apoptosis regulation, evaluation of $I C T 1$ effects on 18 significant and well-characterized signaling molecules in the ZR-75-30 cells was detected by PathScan ${ }^{\circledR}$ intracellular signaling array kit. As a result (Fig. 6), Lv-shICT1(S1)-transfected cells showed enhanced phosphorylation of AMPK $\alpha$ at Thr172. In contrast, Bad phosphorylation at Ser112 and PARS40 phosphorylation at Thr246 was decreased in the Lv-shICT1(S1)-treated ZR-75-30 cells. Hence, it was suggested that the signaling pathways mediated by Bad, AMPK or PRAS40 may be altered after knockdown of ICTI in ZR-75-30 cells.

Efeect of ICT1 knockdown on proteins involved in cell apoptosis or cell cycle in ZR-75-30 cells. The above mentioned data suggested that the regulation of cell apoptosis by ICT1 is closely correlated with Bcl-2 family proteins. We further investigated the expression pattern of Bcl-2 and caspase-3, two proteins that act as the executor and modulator of cell apoptosis (17). As a result, $\mathrm{Lv}$-shICT1(S1) transduction significantly decreased the protein level of Bcl-2. In contrast, the caspase-3 protein level was increased. Moreover, the expression of cell cycle regulatory proteins including CDK1, CDK2 and cyclin B were all significantly downregulated in the Lv-shICT1(S1)infected cells. 
A

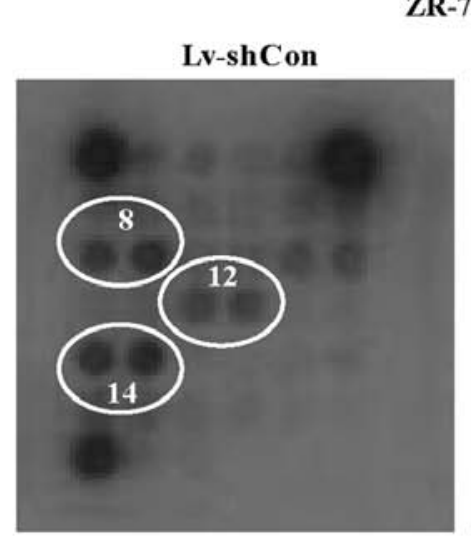

ZR-75-30

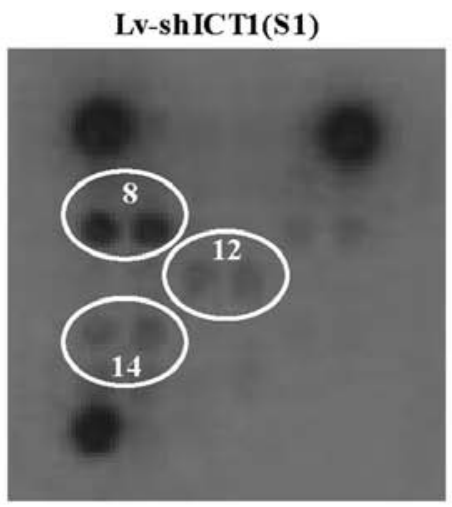

\begin{tabular}{lccc}
\hline No. & Target & Phosphorylation Site & Expression level \\
\hline 8 & AMPKa & Thr172 & up \\
12 & Bad & Ser112 & down \\
14 & PRAS40 & Thr246 & down
\end{tabular}

B

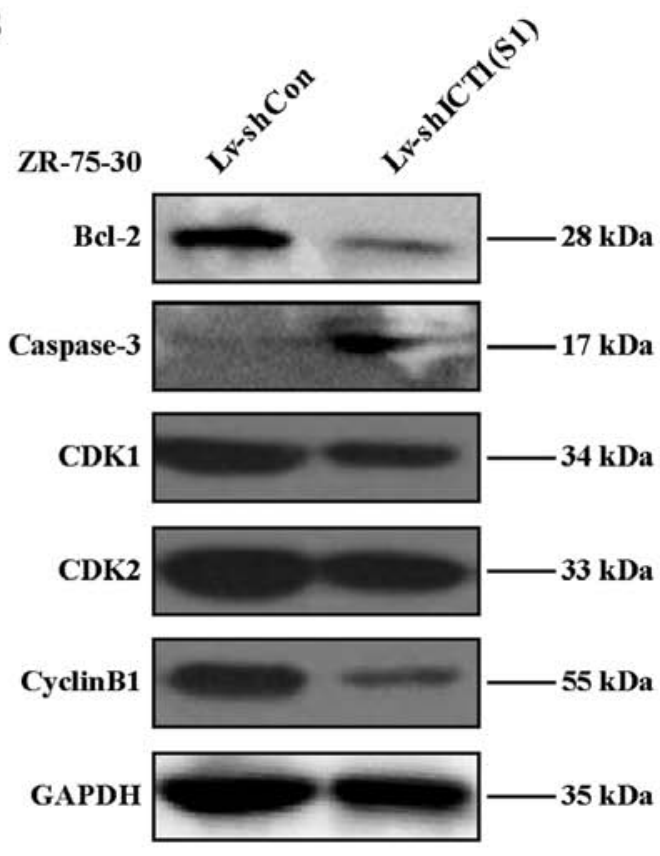

Figure 6. Effect of immature colon carcinoma transcript 1 (ICT1) on downstream proteins in breast cancer cells. (A) Downregulation of ICT1 reduced phospho-BAD (Ser112) and phospho-PRAS40 (Thr246), but increased phospho-AMPK $\alpha$ (Thr172) in breast cancer ZR-75-30 cells. (B) Effect of ICT1 deficiency on expression of apoptosis-related proteins (caspase-3 and Bcl-2) and cell-cycle-related proteins (CDK1, CDK2 and cyclin B) in ZR-75-30 cells was measured by western blotting. Stable housekeeping gene GAPDH was used as the experimental control.

\section{Discussion}

Human breast cancer is one of the most common malignancies diagnosed worldwide and the overall incidence of breast cancer has increased almost 2 -fold over the past 20 years (18). $I C T 1$, a component of the human mitoribosome, has been shown to be involved in the proliferation of various types of cancer cells including HeLa, hepatoblastoma HepG2 and glioblastoma multiforme cells $(14,16)$. In the present study, the role of ICTI in breast cancer cells was explored. Our data revealed that $I C T 1$ deficiency led to the inhibition of proliferation and colony formation, and the $\mathrm{G} 2 / \mathrm{M}$ phase arrest. Consistently, ICT1 knockdown caused cell cycle arrest at the G2/M phase in prostate (19) and colon cancer (20). But in lung cancer cells, the cell cycle was arrested at the G0/G1 phase by ICT1 downregulation leading to cell growth inhibition (21). These differences in the different cell cycle phases may be ascribed to the tumor type.

Moreover, intracellular signaling pathways, apoptosis-related proteins, and cell cycle regulatory proteins were partially altered in breast cancer cells following ICTI knockdown. Cyclin-dependent kinase (CDK)/cyclin complexes play central roles in the control of cell cycle progression in eukaryotic cells (22). For successful entry into mitosis, the activation of the CDK1/cyclin B complex is essential for driving cells into the $M$ phase (23). Meanwhile, the inactive form of CDK1/cyclin B must occur for cell cycle arrest at G2/M transition (24). CDK2 can form complexes with cyclin A and $\mathrm{B}$ to participate in the cell cycle transition from $\mathrm{S}$ phase to premitotic G2 phase and through the G2/M checkpoint (25). $\mathrm{p} 21^{\mathrm{Waf}}, \mathrm{p} 27^{\mathrm{Kipl}}$ and $\mathrm{p} 57^{\mathrm{Kip} 2}$ are considered cyclin-dependent kinase inhibitors that regulate cell cycle distribution (26). In this study, cell cycle arrest in G2/M phases occurred in the ICT1-knockdown cells. It was suggested that the complexes formed with CDK1, cyclin B or CDK2 were suppressed, as protein levels of these proteins were all reduced in the ICT1-knockdown cells. Therefore, the induction of G2/M arrest may be mediated through the inactivation of CDK1cyclin B and CDK2-cyclin B complexes. Decreased activity of CDK2-cyclin A and CDK2-cyclin E may have contributed to the $S$ phase arrest in the ICT1 shRNA-transfected ZR-75-30 cells. It remain to be explored whether ICTI acts as negative regulator of $\mathrm{p} 21^{\text {Waf }}$ and/or $\mathrm{p} 27^{\mathrm{Kip} 1}$; targeting the downstream CDK1 and CDK2 in breast cancer.

Phosphorylation of AMPK, Bad and PRAS40 has been reported to be linked to cell apoptosis regulation $(27,28)$. Intriguingly, the phosphorylation of Bad Ser112, PRAS40 Thr246 and AMPK $\alpha$-Thr172 could be regulated by protein kinase A (PKA), PIM1 and AKT (29,30). Hurley et al demonstrated that the phosphorylation of AMPK $\alpha$ at Thr172 is a determinant factor for AMPK activation (27). Thus, phosphorylation of AMPK, an energy and nutrient sensor, can modulate its downstream signaling targets $(31,32)$. In this investigation, the phospho-AMPK (Thr172) was induced upon knockdown of ICT1, indicating that the AMPK downsteam pathways may contribute to the apoptosis of breast cancer cells.

Bad is a death-promoting member of the BCL-2 family promoting apoptosis through interaction and inhibition of Bcl-xL and Bcl-2 anti-apoptotic function (33). When Bad was phosphorylated at Ser112, Ser136 and Ser155, the sequestration of Bad in the cytosol occurs as a result of the tau form of 14-3-3 proteins that promotes dissociation of Bcl-xL and Bcl-2 (34,35). Our data demonstrated that Bad Ser112 phosphorylation was decreased in the ICTI-knockdown cells, 
suggesting an increased binding of Bad to Bcl-xL and Bcl-2 and subsequent promotion of cell apoptosis.

PRAS40 has been identified as a proline-rich substrate of Akt and is involved in cell survival, proliferation, and mobility $(28,36)$. Wang et al (36) showed that a decrease in PRAS40 (Thr246) phosphorylation is associated with tumor cell apoptosis. During tumor cell growth progression in human melanocytes, the phospho-Thr246 of PRAS40 was increased (36). In this study, reduced phospho-Thr246 PRAS40 was observed following knockdown of ICT1 contributing to the induction of apoptosis in breast cancer cells. Moreover, caspase-3, a death protease that is usually activated during cell death program (37) was found to be overexpressed in ZR-75-30 cells with ICT1 knockdown.

In conclusion, our results demonstrated that ICT1 may play a positive role in breast cancer cell proliferation by regulating cell cycle progression and apoptosis. Knockdown of ICT1 may be used as a new therapeutic approach for the therapy for breast cancer. Furthermore, shRNA-mediated ICT1-targeted therapy warrants further investigation in preclinical and clinical studies.

\section{Acknowledgements}

The authors are thankful for the financial support from the Natural Science Foundation of Zhejiang Province, China (no. LY12H16030); the Foundation of Health Department of Zhejiang Province, China (no. 2011BCA015) and the Traditional Chinese Medical Research Foundation of Zhejiang Province, China (no. 2011ZA016).

\section{References}

1. Ferlay J, Héry C, Autier P and Sankaranarayanan R: Global burden of breast cancer. In: Breast Cancer Epidemiology. Li C (ed). Springer, New York, pp1-19, 2010.

2. Al-Hajj M, Wicha MS, Benito-Hernandez A, Morrison SJ and Clarke MF: Prospective identification of tumorigenic breast cancer cells. Proc Natl Acad Sci USA 100: 3983-3988, 2003.

3. Key T, Appleby P, Barnes I, Reeves G and Endogenous H; Endogenous Hormones and Breast Cancer Collaborative Group: Endogenous sex hormones and breast cancer in postmenopausal women: Reanalysis of nine prospective studies. J Natl Cancer Inst 94: 606-616, 2002.

4. Skobe M, Hawighorst T, Jackson DG, Prevo R, Janes L, Velasco P, Riccardi L, Alitalo K, Claffey K and Detmar M: Induction of tumor lymphangiogenesis by VEGF-C promotes breast cancer metastasis. Nat Med 7: 192-198, 2001.

5. Müller A, Homey B, Soto H, Ge N, Catron D, Buchanan ME, McClanahan T, Murphy E, Yuan W, Wagner SN, et al: Involvement of chemokine receptors in breast cancer metastasis. Nature 410: 50-56, 2001.

6. Clarke M, Collins R, Darby S, Davies C, Elphinstone P, Evans V, Godwin J, Gray R, Hicks C, James S, et al; Early Breast Cancer Trialists' Collaborative Group (EBCTCG): Effects of radiotherapy and of differences in the extent of surgery for early breast cancer on local recurrence and 15-year survival: An overview of the randomised trials. Lancet 366: 2087-2106, 2005.

7. Slamon DJ, Leyland-Jones B, Shak S, Fuchs H, Paton V, Bajamonde A, Fleming T, Eiermann W, Wolter J, Pegram M, et al: Use of chemotherapy plus a monoclonal antibody against HER2 for metastatic breast cancer that overexpresses HER2. N Engl J Med 344: 783-792, 2001.

8. Meraviglia S, Eberl M, Vermijlen D, Todaro M, Buccheri S, Cicero G, La Mendola C, Guggino G, D'Asaro M, Orlando V, et al: In vivo manipulation of Vgamma9Vdelta2 T cells with zoledronate and low-dose interleukin-2 for immunotherapy of advanced breast cancer patients. Clin Exp Immunol 161: 290-297, 2010.
9. Das S, Ferlito M, Kent OA, Fox-Talbot K, Wang R, Liu D, Raghavachari N, Yang Y, Wheelan SJ, Murphy E, et al: Nuclear miRNA regulates the mitochondrial genome in the heart. Circ Res 110: 1596-1603, 2012.

10. Dames S, Eilbeck K and Mao R: A high-throughput nextgeneration sequencing assay for the mitochondrial genome. Methods Mol Biol 1264: 77-88, 2015.

11. Handa Y, Inaho N and Nameki N: YaeJ is a novel ribosome-associated protein in Escherichia coli that can hydrolyze peptidyl-tRNA on stalled ribosomes. Nucleic Acids Res 39: 1739-1748, 2011.

12. Akabane S, Ueda T, Nierhaus KH and Takeuchi N: Ribosome rescue and translation termination at non-standard stop codons by ICT1 in mammalian mitochondria. PLoS Genet 10: e1004616, 2014.

13. Richter R, Rorbach J, Pajak A, Smith PM, Wessels HJ, Huynen MA, Smeitink JA, Lightowlers RN and ChrzanowskaLightowlers ZM: A functional peptidyl-tRNA hydrolase, ICT1, has been recruited into the human mitochondrial ribosome. EMBO J 29: 1116-1125, 2010.

14. Handa Y, Hikawa Y, Tochio N, Kogure H, Inoue M, Koshiba S, Güntert P, Inoue Y, Kigawa T, Yokoyama S, et al: Solution structure of the catalytic domain of the mitochondrial protein ICT1 that is essential for cell vitality. J Mol Biol 404: 260-273, 2010.

15. Kogure H, Handa Y, Nagata M, Kanai N, Güntert P, Kubota K and Nameki N: Identification of residues required for stalledribosome rescue in the codon-independent release factor YaeJ. Nucleic Acids Res 42: 3152-3163, 2014.

16. Xie R, Zhang Y, Shen C, Cao X, Gu S and Che X: Knockdown of immature colon carcinoma transcript-1 inhibits proliferation of glioblastoma multiforme cells through Gap 2/mitotic phase arrest. Onco Targets Ther 8: 1119-1127, 2015.

17. Sparrow JR and Cai B: Blue light-induced apoptosis of A2E-containing RPE: Involvement of caspase-3 and protection by Bcl-2. Invest Ophthalmol Vis Sci 42: 1356-1362, 2001.

18. Yan LX, Huang XF, Shao Q, Huang MY, Deng L, Wu QL, Zeng YX and Shao JY: MicroRNA miR-21 overexpression in human breast cancer is associated with advanced clinical stage, lymph node metastasis and patient poor prognosis. RNA 14: 2348-2360, 2008.

19. Wang Z, Xu D, Gao Y, Liu Y, Ren J, Yao Y, Yin L, Chen J, Gan S and Cui X: Immature colon carcinoma transcript 1 is essential for prostate cancer cell viability and proliferation. Cancer Biother Radiopharm 30: 278-284, 2015.

20. Lao X, Feng Q, He G, Ji M, Zhu D, Xu P, Tang W, Xu J and Qin X: Immature colon carcinoma transcript-1 (ICT1) expression correlates with unfavorable prognosis and survival in patients with colorectal cancer. Ann Surg Oncol 23: 3924-3933, 2016.

21. Wang Y, He J, Zhang S, Yang Q, Wang B, Liu Z and Wu X: Knockdown of immature colon carcinoma transcript 1 inhibits proliferation and promotes apoptosis of non-small cell lung cancer cells. Technol Cancer Res Treat: Jul 13, 2016 (Epub ahead of print). doi: 20161533034616657977.

22. Arellano M and Moreno S: Regulation of CDK/cyclin complexes during the cell cycle. Int J Biochem Cell Biol 29: 559-573, 1997.

23. Ji YB, Wu D, Dai QC, Guo L and Chen N: The research on the medicinal value of Amaryllidaceae plants. Appl Mech Mater 411-414: 3223-3226, 2013.

24. Cmielová $\mathrm{J}$ and Rezáčová $\mathrm{M}$ : $\mathrm{p} 21^{\mathrm{Cip} 1 / \text { Waf1 }}$ protein and its function based on a subcellular localization [corrected]. J Cell Biochem 112: 3502-3506, 2011.

25. Caputi M, Russo G, Esposito V, Mancini A and Giordano A: Role of cell-cycle regulators in lung cancer. J Cell Physiol 205: 319-327, 2005.

26. Lim S and Kaldis P: Cdks, cyclins and CKIs: Roles beyond cell cycle regulation. Development 140: 3079-3093, 2013.

27. Hurley RL, Anderson KA, Franzone JM, Kemp BE, Means AR and Witters LA: The $\mathrm{Ca}^{2+} /$ calmodulin-dependent protein kinase kinases are AMP-activated protein kinase kinases. J Biol Chem 280: 29060-29066, 2005.

28. Morgensztern D and McLeod HL: PI3K/Akt/mTOR pathway as a target for cancer therapy. Anticancer Drugs 16: 797-803, 2005.

29. Garcia-Haro L, Garcia-Gimeno MA, Neumann D, Beullens M, Bollen $M$ and Sanz P: Glucose-dependent regulation of AMP-activated protein kinase in MIN6 beta cells is not affected by the protein kinase A pathway. FEBS Lett 586: 4241-4247, 2012.

30. Xu J, Zhang T, Wang T, You L and Zhao Y: PIM kinases: An overview in tumors and recent advances in pancreatic cancer. Future Oncol 10: 865-876, 2014. 
31. Meisse D, Van de Casteele M, Beauloye C, Hainault I, Kefas BA, Rider MH, Foufelle F and Hue L: Sustained activation of AMP-activated protein kinase induces c-Jun N-terminal kinase activation and apoptosis in liver cells. FEBS Lett 526: 38-42, 2002.

32. Shao JJ, Zhang AP, Qin W, Zheng L, Zhu YF and Chen X: AMP-activated protein kinase (AMPK) activation is involved in chrysin-induced growth inhibition and apoptosis in cultured A549 lung cancer cells. Biochem Biophys Res Commun 423: 448-453, 2012.

33. Chiang CW, Kanies C, Kim KW, Fang WB, Parkhurst C, Xie M, Henry T and Yang E: Protein phosphatase 2A dephosphorylation of phosphoserine 112 plays the gatekeeper role for BAD-mediated apoptosis. Mol Cell Biol 23: 6350-6362, 2003.

34. Peso LD, González-García M, Page C, Herrera R and Nuñez G: Interleukin-3 induced phosphorylation of BAD through protein kinase Akt. Science 278: 687-689, 1997.
35. Jin YP, Fishbein MC, Said JW, Jindra PT, Rajalingam R, Rozengurt E and Reed EF: Anti-HLA class I antibody-mediated activation of the PI3K/Akt signaling pathway and induction of $\mathrm{Bcl}-2$ and $\mathrm{Bcl}-\mathrm{xL}$ expression in endothelial cells. Hum Immunol 65: 291-302, 2004.

36. Wang $\mathrm{H}$, Zhang Q, Wen Q, Zheng Y, Lazarovici P, Jiang H, Lin J and Zheng W: Proline-rich Akt substrate of 40kDa (PRAS40): A novel downstream target of PI3k/Akt signaling pathway. Cell Signal 24: 17-24, 2012.

37. Porter AG and Jänicke RU: Emerging roles of caspase-3 in apoptosis. Cell Death Differ 6: 99-104, 1999. 